modifications, ${ }^{2}$ to fibrinopeptide $\mathrm{B} \beta 1-42)(\mathrm{FpB} \beta 1-42)^{3}$ with modifications ${ }^{2}$ and to $\beta$-thromboglobulin $(\beta \mathrm{TG})^{4}$ with modifications. ${ }^{2}$ Serum cholesterol and triglycerides were measured direct $^{5}$ while high density lipoprotein cholesterol (HDLC) was estimated by precipitation of $\beta$-and prebeta-lipoproteins and measurement of cholesterol in the $\alpha$-lipoprotein. ${ }^{5}$

Data from these patients were compared with data from age-matched controls (Table 1). No significant differences between patients with gout and controls were found.

Spearman rank correlation coefficients were calculated between FpA, FpB $\beta 1-42$ and BTG and lipid concentrations, alcohol consumption, and weight as the data on alcohol and weight tend not to be distributed normally. There were only two significant correlations--that is, cholesterol in mmol/l with $\mathrm{FpA}$ in $\mathrm{pmol} / \mathrm{l}$ and HDLC in mmol/l with $\mathrm{FpB} \beta 1-42$ in $\mathrm{pmol} / \mathrm{l}(\mathrm{p}<0.05)$.

Correlation results must be considered with care as this was a study on small numbers of patients. Furthermore, it must be remembered that abnormalities of coagulation detected in vitro are not necessarily present in vivo nor do they necessarily have a causal relationship with thrombosis.

We concluded that modern methods to assess coagulation and platelet function did not show any significant abnormalities in patients with primary gout.

\section{References}

1 Nossel H L, Yudelman I, Canfield R E, et al. Measurement of fibrinopeptide $\mathbf{A}$ in human blood. J Clin Invest 1974; 54: 43-53.

2 Lane D A, Ireland H, Wolff S, Boots M, Pegrum G D. Simultaneous measurement of thrombin and plasmin activities and platelet releasing stimuli in plasma. Br J Haematol 1981; 47: 630.

3 Nossel H L, Wasser J, Kaplan K L, La Gamma K S, Yudelman I, Canfield R E. Sequence of fibrinogen proteolysis and platelet release after intra-uterine infusion of hypertonic saline.J Clin Invest 1979; 64: 1371-8.

4 Bolton A E, Ludlam C A, Moore S, Pepper D S, Cash J D. Three approaches to the radioimmunoassay of human $\beta$-thromboglobulin. Br J Haematol 1976; 33: 233-8.

5 Smith L, Lucas D, Lehnus G. Automated measurement of total cholesterol and triglycerides, in 'tandem', on the Discrete Sample Analyser Guildford System 3500. Clin Chem 1979; 25: 439-42.

\title{
Long term comparison of azapropazone with allopurinol in control of chronic gout and hyperuricaemia
}

\author{
J. S. TEMPLETON \\ From the International Clinical Research Department, A. H. Robins Co Limited
}

Allopurinol is the standard agent used to lower serum urate concentration and does so by its ability to inhibit xanthine oxidase. Azapropazone is a non-steroidal anti-inflammatory drug (NSAID) that has been shown to inhibit urate monohydrate crystal-induced inflammation in the rat and in $\operatorname{man},{ }^{1}$ to reduce serum urate concentration in patients with rheumatoid arthritis, chronic gout, and hyperuricaemia ${ }^{2}$ and to be effective in the treatment of both acute and chronic gout. $^{3}$

In this study, 24 separate investigators recruited suitable patients with chronic gout or hyperuricaemia or both who had been receiving allopurinol treatment satisfactorily for at least three months before entry to the study. Patients were then allocated to one of two treatment groups, either continuing to receive allopurinol and followed up every two months for up to six months, or starting azapropazone $600 \mathrm{mg}$ twice daily and seen roughly every month for up to six months. Both groups were comparable in respect of age, sex, duration of disease, allopurinol dose at entry, diagnosis, and eligibility for the study.

Data is so far available on 155 patients who changed to azapropazone and 122 who continued to receive allopurinol. Control of serum urate concentration was comparable in both groups (Table 1). In both groups, serum urate remained remarkably constant with two points worthy of mention.

(1) Azapropazone lowered urate concentration slightly after two weeks and indeed further studies are planned to see if this in fact occurs earlier than two weeks.
(2) There is no evidence of increase in serum urate concentrations in those patients who changed from allopurinol to azapropazone. This is contrary to the findings in a group of patients in whom allopurinol treatment was suddenly discontinued. ${ }^{4}$

During the study period acute attacks of gout were less frequent in those patients taking azapropazone than in those who continued to take allopurinol. Indeed, an 'attack rate' during the first four weeks of study in those patients from both groups who could be classed as susceptible - that is, those with positive history of acute gout-showed no acute attacks in 109 patients receiving azapropazone and six acute attacks in 103 patients receiving allopurinol.

Adverse effects, particularly relating to the upper gastrointestinal tract, occurred more often in patients 
Abstracts Suppl p 93

receiving azapropazone and there was also a higher prevalence of abnormal renal function (judged by raised blood urea or serum creatinine or both) in this group. Analysis of the data on renal function, however, reveals that in the group treated with azapropazone the increase in urea or creatinine occurred principally during the first two weeks of treatment and did not rise further.

In addition, out of 32 patients changed to azapropazone who were receiving additional analgesics at the start of the study, 22 were able to stop this analgesic(s), 10 continued them, and five more had to start taking-usually intermittently-additional analgesics. Of 39 patients who continued taking allopurinol, nine were able to stop additional analgesics, nine continued on the same additional analgesics as before, and 21 had to start treatment with an additional analgesic.

Thus, azapropazone would appear to be a useful alternative drug for the long term control of patients with chronic gout or hyperuricaemia, or both. Its two possible important advantages are that it is a single drug
Table 1 Serum urate concentration of treated patients (normal values $0 \cdot 14-0 \cdot 45$ mmolll)

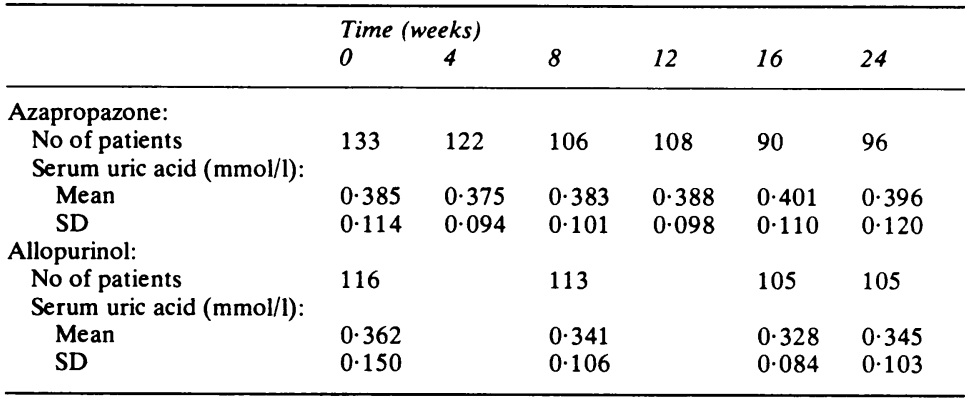

treatment for acute and chronic gout and it provides a considerable measure of analgesic effect, which allopurinol cannot do, for those patients who have painful concurrent degenerative joint disease such as osteoarthritis, cervical spondylosis, backache, etc.

\section{References}

1 Dieppe P A, Doherty M, Whicher J T, Walters $G$. The treatment of gout with azapropazone: clinical and experimental studies. European Journal of Rheumatol-

2 Thomas A L, Majoos F L, Nuki G. Preliminary studies with azapropazone in gout and hyperuricaemia. In: Fenclofenac in arthritis. Proceedings of 19th European Congress of Rheumatology, Wiesbaden 1979. London: Royal Society of Medicine.

3 Frank $O$. Investigation of the uricosuric action of azapropazone. $Z$ Rheumatol 1971; 30: 368-73.

4 Loebl W Y, Scott J T. Withdrawal of allopurinol in patients with gout. Ann Rheum Dis 1974; 33: 304-7. ogy and Inflammation 1981; 4: 392-400.

\title{
Gout with apparent resistance to allopurinol
}

\author{
T. GIBSON, H. A. SIMMONDS, A. V. RODGERS, G. J. HUSTON, D. R. WEBSTER, \\ J. MUNRO, AND P. EMERY
}

From Guy's Hospital, London SE1

The dose of allopurinol necessary to induce sustained normouricaemia in gout rarely exceeds $300 \mathrm{mg}$ daily. We describe a patient with apparent resistance to conventional doses of allopurinol and probenecid. The study was designed to evaluate the response to varying doses of allopurinol and to determine whether the hyperuricaemia and the reported lack of effect of allopurinol were related to some unusual disturbance of purine metabolism.

CASE REPORT

A 51 year old man had experienced intermittent episodes of gout confirmed by the demonstration of intra-articular urate crystals for 20 years. Various combinations of anti-inflammatory and hypouricaemic drugs had failed to exert a detectable effect on his recurrent arthritis. At the time of referral he was obese but exhibited no tophi and was normotensive. One brother had a history of gout. His alcohol consumption was modest, though he had transient liver dysfunction; liver biopsy showed no abnormality. Glomerular filtration rate $\left({ }^{51} \mathrm{Cr}\right.$ EDTA) was normal at 100 $\mathrm{ml} / \mathrm{min} / 1.73 \mathrm{~m}^{2}$ but his urine was of constant $\mathrm{pH}$ and renal concentrating ability was impaired. He was admitted to hospital on three separate occasions for investigation. After four days on a low purine, caffeine free diet he underwent five periods of treatment with allopurinol in doses increasing from $200 \mathrm{mg}$ to $1200 \mathrm{mg}$.

Each treatment period lasted a further four days except the last (1200 $\mathrm{mg} /$ day), which was curtailed after two days. The studies were conducted in a metabolic ward. Table 1 shows the results of daily investigations conducted before and during each treatment period. Estimations of uric acid, purines, and allopurinol metabolites were performed as previously described. ${ }^{12}$ Red cell lysates were investigated for enzyme deficiencies, which are acknowledged 